\title{
UNIVERSITYOF
}

FORWARD

THINKING

WESTMINSTER用

WestminsterResearch

http://www.westminster.ac.uk/westminsterresearch

\section{Pregnancy influences the selection of appropriate reference genes in mouse tissue: Determination of appropriate reference genes for quantitative reverse transcription PCR studies in tissues from the female mouse reproductive axis Berruien, N., Murray, J.F. and Smith, C.L.}

NOTICE: this is the authors' version of a work that was accepted for publication in Gene. Changes resulting from the publishing process, such as peer review, editing, corrections, structural formatting, and other quality control mechanisms may not be reflected in this document. Changes may have been made to this work since it was submitted for publication. A definitive version was subsequently published in Gene, 801, 30 October 2021, 145855.

The final definitive version in Gene is available online at:

\section{https://doi.org/10.1016/..gene.2021.145855}

(C) 2021. This manuscript version is made available under the CC-BY-NC-ND 4.0 license https://creativecommons.org/licenses/by-nc-nd/4.0/

The WestminsterResearch online digital archive at the University of Westminster aims to make the research output of the University available to a wider audience. Copyright and Moral Rights remain with the authors and/or copyright owners. 
1 Title: Pregnancy influences the selection of appropriate reference genes in mouse tissue:

2 Determination of appropriate reference genes for quantitative reverse transcription PCR 3 studies in tissues from the female mouse reproductive axis.

Abstract

Selecting stably expressed reference genes which are not affected by physiological or pathophysiological conditions is crucial for reliable quantification in gene expression studies. This study examined the expression stability of a panel of twelve reference genes in tissues from the female mouse reproductive axis and the uterus. Gene expression studies were carried out using reverse transcriptase quantitative polymerase chain reaction (RT-qPCR). cDNA was synthesised 11 from RNA extracted from hypothalami, pituitaries, ovaries and uteri of female mice at ages representing weaning, puberty and adulthood as well as pregnancy (13 \pm 1 days post-coitus) $(n=a$ minimum of 3 at each age and at pregnancy). The reference genes examined included $18 \mathrm{~s}$, Actb, Atp5b, B2m, Canx, Cyc1, Eif4a2, Gapdh, Rpl13a, Sdha, Ubc and Ywhaz. The RT-qPCR raw data were imported into the qBASE+ software to analyse the expression stability using GeNorm. These data were also subsequently analysed using other software packages (Delta CT, Normfinder,

BestKeeper). A comprehensive ranking was conducted considering all stability rankings generated from the different software analyses. $B 2 m$ and Eif4a2 deviated from the acceptable range for amplification efficiency and therefore were excluded from the further analyses. The stability of the reference genes is influenced by the software used for the analysis with BestKeeper providing markedly different results than the other analyses. GeNorm analysis of tissues taken at different ages but not including pregnant animals, indicated that the expression of the reference genes is tissue specific with the most stable genes being: in the hypothalamus, Canx and Actb; in the pituitary, Sdha and Cyc1; in the ovary, 18s, Sdha and Ubc; and in the uterus, Ywhaz, Cyc1, Atp5b, $18 s$ and Rp/13a. The optimal number of reference genes to be used was determined to be 2 in the first three tissues while in the uterus, the V-score generated by the GeNorm analysis was higher 
than 0.15 suggesting that 3 or more genes should be used for normalisation. Inclusion of tissues

28 from pregnant mice changed the reference genes identified as being the most stable: Ubc and Sdha 29 were the most stable genes in the hypothalamus, pituitary and the ovary. The addition of pregnant 30 tissue had no effect on the stability of the genes in uterus (Ywhaz, Cyc1, Atp5b, 18s and Rp/13a). 31 Identification of these stable reference genes will be of use to those interested in studying female study also signifies the importance of re-examining reference gene stability if the experimental conditions are changed as shown with the introduction of pregnancy as a new factor in this research.

\section{Introduction}

Mammalian female fertility requires the co-ordinated activity of the reproductive axis (the hypothalamus, pituitary and ovaries hence also called the hypothalamo-pituitary-ovarian axis (HPO axis)) and the uterus. Co-ordination between these four organs is predominately hormonal but also includes regulation by both the nervous and immune systems. The regulation is dynamic: it changes both over the life cycle (prepubertal, puberty, adulthood, pregnancy, lactation and senescence) and over the reproductive cycle (humans $=$ menstrual cycle; most other mammals $=$ oestrous cycle) . Effective communication between the hypothalamus, pituitary and ovary ensure that an oocyte/oocytes (the female gamete) is/are ovulated in each reproductive cycle, that the female is receptive to a male at the ideal time to maximize the chances of fertilization and that the uterus is prepared to receive and nurture any resulting embryo/embryos. In order to achieve all these functions both the ovary and the uterus undergo cycles of tissue remodelling. It is therefore likely that within each of the four organs there are significant changes in gene expression dependent on the reproductive status of the female. Analysis of gene expression in the female reproductive axis can be determined by reverse transcription real-time quantitative PCR (RT-qPCR), however interpretation of these results requires the identification of stable reference genes. 
52 The most commonly used reference genes to normalise expression include $18 \mathrm{~S}$ and $28 \mathrm{~S}$ ribosomal

53 RNA subunits (rRNA), 18s and 28S, glyceraldehyde-3-phosphate dehydrogenase, GAPDH, and 54 actin-beta, ACTB (Suzuki, et al., 2000). A significant portion of total RNA extracted from tissue is 55 rRNA, transcription of which is affected by chromatin remodelling and influenced by biological 56 factors, therefore the reliability of rRNA genes for normalisation has been questioned 57 (Vandesompele, et al., 2002). Expression of both GAPDH and ACTB have been reported to vary in 58 human adult tissues (Warrington, et al., 2000) and are altered by mitogenic stimuli (Radonić, et al., 59 2004). Gene expression stability may also be influenced by physiological conditions: in a 60 comparison of mouse brain regions, it was observed that there was a significant down-regulation of

61 candidate reference genes in adult compared to day 7 mice (Boda, et al., 2009). Reliance on a 62 single reference gene may lead to erroneous gene normalisation and hence the minimum 63 information for publication of quantitative real-time PCR experiments (MIQE) guidelines recommend 64 evaluating whether two, three or more reference genes are required for normalisation 65 (Vandesompele, et al., 2002; Bustin, et al., 2009).

66 To determine reference gene stability the most commonly used analytical tools include: GeNorm 67 (Vandesompele, et al., 2002), NormFinder (Andersen, et al., 2004), BestKeeper (Pfaffl, et al., 2004), 68 Delta CT and comprehensive gene stability. Here we have assessed twelve reference genes by RT69 qPCR using each of the above analyses to check gene stability in the female mouse hypothalamus, 70 pituitary, ovary and uterus at stages in the reproductive life cycle (pre-weaning, puberty, adult) and 71 during pregnancy.

\section{Materials and Methods:}

\section{Animals}

Female C57BL/6 mice were housed in rooms with a 12:12 hour light: dark cycle (lights on at 0700) at $21 \pm 1^{\circ} \mathrm{C}$. Ad libitum access to both standard laboratory chow and water were provided for all 
77 animals. Ethics approval for this study was granted by the University of Westminster (Ethics

78 Approval VRE1415-0209). These studies were done in full accordance with the Home Office's 79 Animal (Scientific Procedures) Act (1986).

80 Animals were killed by dislocation of the neck followed immediately by decapitation to allow both

81 the brain and pituitary to be dissected free as soon as possible. Likewise, both the ovaries and the uterus were dissected free from the abdomen immediately after death. Hypothalami, pituitaries, ovaries and uteri were removed from virgin female mice aged 2, 6, 9/10 and 14 weeks and pregnant mice (9 weeks at mating and approximately 13 days post-coitus (dpc) of gestation based on detection of mating plug). Tissues from at least 3 mice for each age group and pregnancy were used. All tissues were immediately placed in RNALater ${ }^{\circledR}$ and stored at $-80^{\circ} \mathrm{C}$ until RNA isolation commenced.

\section{RNA Isolation and cDNA Synthesis}

RNA was extracted using TRIzol (Invitrogen ${ }^{\mathrm{TM}}$, ThermoScientific, UK) and then purified using a RNeasy micro kit (Qiagen, Germany). Total RNA quality and concentration were measured using a Nanodrop $2000^{\circledR}$ (a 260:280 nm ratio > 1.8 was deemed acceptable quality). cDNA was synthesised using SuperScript II Reverse Transcriptase (200U), approximately 300 ng RNA and random hexamer primers (150ng, Invitrogen ${ }^{\mathrm{TM}}$, ThermoScientific, UK). The cDNA samples were stored at $20^{\circ} \mathrm{C}$ until required.

\section{Determination of reference gene amplification efficiency}

96 The PCR amplification efficiencies and $\mathrm{R}^{2}$ coefficients were determined for all reference genes 97 included in this study. A standard curve for each tissue (hypothalamus, pituitary gland, ovary and uterus) was generated using pooled cDNA from all age groups plus pregnant samples. The pooled cDNA (starting concentration $1 \mu \mathrm{g}$ ) was used to create 1:10 serial dilutions spanning 5 orders of magnitude and each concentration was assessed in triplicate. The primer efficiencies were 
101 generated using the CFX96 C1000 touch real time qPCR machine and CFX Maestro software (BIO-

102 RAD, UK).

103

104

105

106

107

108

109

\section{The GeNorm reference gene panel and RT-qPCR}

The GeNorm kit, which contains a panel of 12 genes (18s, Actb, Atp5b, B2m, Canx, Cyc1, Eif4a2, Gapdh, Rp/13a, Sdha, Ubc and Ywhaz; Table 1), was used to select the reference genes (PrimerDesign, UK). Each RT-qPCR mix consisted of: master mix (premixed with SYBR green) (10X PrecisionPLUS ${ }^{\mathrm{TM}}$, UK), reference primers (reference gene details listed in Table 1) (6 pmol) and 25 ng of cDNA. Reactions, done in duplicate, were placed in a thermocycler (CFX96 C1000 touch, BIO-RAD, UK) and underwent the following cycle: initial activation at $95^{\circ} \mathrm{C}$ for 2 minutes; followed by 40 cycles of denaturing at $95^{\circ} \mathrm{C}$ for 15 seconds and annealing and extension at $60^{\circ} \mathrm{C}$ for 30 seconds; and ending with a dissociation melt curve $\left(60-95^{\circ} \mathrm{C}\right)$. The size of each amplicon for each reaction was determined by electrophoresis on a $2 \%$ agarose gel (Table 1 ).

\section{Determination and validation of reference gene stability}

GeNorm calculates a normalisation factor based on multiple reference genes. GeNorm software hypothesises that two or more normalisers (reference genes) should have the same expression ratio across all samples and experimental conditions. A measure, "M", which reflects the reference gene stability is established through the standard deviation of the logarithmically transformed expression cycle threshold $(\mathrm{CT})$ ratios. The most stable genes will have the lowest " $\mathrm{M}$ " values. The normalisation factor is then calculated using the geometric mean from expression levels of the most stable reference genes. This software recommends the use of at least 2-3 of the most stable reference genes to calculate the normalisation factor as adding a fourth gene does not significantly contribute to the expression stability analysis (Vandesompele, et al., 2002).

NormFinder is a mathematical model describing the RT-qPCR log CT values, estimation of interand intra-group variations, sub-group analyses and, finally, the calculation of stability values of the reference genes examined. The reference genes are then ranked according to their stability value 
with the most stable gene having the lowest stability value (Andersen, et al., 2004; Palombella, et 127 al., 2017).

BestKeeper was developed on the basis that the most stable reference genes show the least variability in their CT values across the samples examined (Pfaffl, et al., 2004). The software algorithm utilises the reference gene's CT data calculating the geometric mean, the arithmetic mean, and standard deviation (St. Dev); represented as minimum CT, maximum CT and CT St. Dev. Reference genes with a CT St. Dev greater than one are considered unstable. To be able to choose more than one stable gene, a pair-wise correlation analysis is done to estimate the inter-gene relations of all possible pairs: a BestKeeper index combines the most stably expressed reference genes. Then, the Pearson correlation coefficient, the coefficient of determination and the p-value statistically describe the correlation between this index and the reference genes (Pfaffl, et al., 2004; Palombella, et al., 2017).

Delta-CT is based on a process of exclusion: the relative expression of a pair of genes is compared in different samples using the delta CT and St. Dev. Stable genes would not show any variability in the different samples. This procedure is used with more than one pair and various conditions and pairs that show variable expression among samples, and hence have fluctuating expression stability, are excluded.

Comprehensive ranking. In addition to these four algorithms, RefFinder (web-based tool) was used to generate an overall comprehensive ranking for the reference genes. The RefFinder algorithm assigns an appropriate weight for each gene and by incorporating the ranking numbers from GeNorm, NormFinder, BestKeeper and DeltaCT, calculating the geometric mean of the weights for the overall final ranking of genes (Xie, et al., 2012). 
Results:

Reference gene amplication efficiency

153

154

155

156

157

158

159

160

161

162

163

164

165

166

167

168

169

170

171

17

173

Amplification efficiencies were determined for the GeNorm panel and ten of the reference genes (18s, Actb, Atp5b, Canx, Cyc1, Gapdh, Rpl13a, Sdha, Ubc and Ywhaz) had amplification efficiencies in the acceptable range of $90-100 \%$ (Table 2). Two of the twelve reference genes, B2m and Eif4a2, were found to have amplification efficiencies deviating from the accepted range, despite numerous repetitions and troubleshooting, hence they were excluded from the subsequent GeNorm analyses.

\section{GeNorm Analyses}

RT-qPCR amplification of the reference genes (18s, Actb, Atp5b, Canx, Cyc1, Gapdh, Rp/13a, Sdha, Ubc and Ywhaz) was carried out on tissues from the female reproductive axis in pre-weaned ( 2 week), pubertal ( 6 week), adult $(9,10$ and 14 week) and pregnant mice (9 weeks $13 \mathrm{dpc}$ ) with three animals in each group. All genes amplified before 28 cycles and the minimum and maximum CT values for each reference gene are presented in Figure 1A. To determine the optimal number of genes for the RT-qPCR GeNorm analysis, as advised in MIQE guidelines, a pair-wise variation (Vscore) was calculated using the GeNorm software (Figure 2). The V-score was below 0.15 for the hypothalamus, pituitary and ovary (Figure $2 \mathrm{~A}-\mathrm{C}$ ) and the mean pairwise variation indicated that two genes should be used for normalisation; however, the V-score was higher than 0.15 for the uterus (Figure $2 \mathrm{D}$ ) suggesting that 3 or more genes should be used for normalisation.

\section{Effect of pregnancy on reference gene stability}

The RT-qPCR data were organised into two sets: A) age groups alone (excluding the pregnant samples) and B) all the samples (age groups including pregnant samples). Using the GeNorm tool, inclusion of pregnant samples changed the stability values of the reference genes in the hypothalamus, pituitary and ovary (Figure 3). 
In the female mouse hypothalamus, the non-pregnant data set analysed by GeNorm identified that

Canx, Actb, Atp5b and Ywhaz (listed in order of stability: highest to lowest; all lists that follow are presented in the same way) were the most stable genes while Cyc1 and 18 s were the least stable genes (Figure 3: A1). When the pregnant samples were included, Cyc1 and 18s remained the least stable genes while Ubc/Sdha, Ywhaz and Canx became the most stable genes in the hypothalamus (Figure 3: B1).

genes in the non-pregnant data set (Figure 3: A2) whilst Ubc, Sdha, Atp5b and 18s were the most stable genes when the pregnant samples were included in the analysis (Figure 3: B2). The least stable genes for the pituitary were Canx and Ywhaz for both data sets. The remaining genes showed a slight fluctuation in the expression.

In the GeNorm analysis of the ovary, $18 s / S d h a, U b c$ and Ywhaz were identified as the most stable genes in the non-pregnant data set (Figure 3: A3). When pregnant samples were included Sdha, Ubc, Ywhaz and Atp5b were identified as the most stable genes (Figure 3: B3). Actb and Cyc1 were both identified as the least stable genes in the female mouse ovary in both the non-pregnant and with pregnant data sets.

In the uterus, fewer genes had stability values less than 1 compared to the other tissues. There was no difference in the ranking for the two data sets (Figure 3: A4 and B4). The most stably expressed genes identified by the GeNorm analysis were Ywhaz, Cyc1, Atp5b and 18s for both data sets

(Figure 3: A4 and B4). Sdha and Ubc were the least stable genes in both data sets in the uterus (Figure 3: A4 and B4).

Comparison of gene stability using GeNorm NormFinder, BestKeeper, Delta CT and Comprehensive ranking

Data from the RT-qPCR of the panel of genes (18s, Actb, Atp5b, Canx, Cyc1, Gapdh, Rp/13a, Sdha, Ubc and Ywhaz) in the hypothalamus, pituitary gland, ovary, and uterus were also analysed using 
199 NormFinder, BestKeeper, Delta CT and Comprehensive ranking and are shown below for the two 200 data sets: the non-pregnant samples only (- pregnant) and the non-pregnant and pregnant samples (+ pregnant).

\section{Summary of the most stable genes in each tissue using GeNorm, NormFinder, BestKeeper, Delta CT and Comprehensive ranking analyses:}

\section{Hypothalamus}

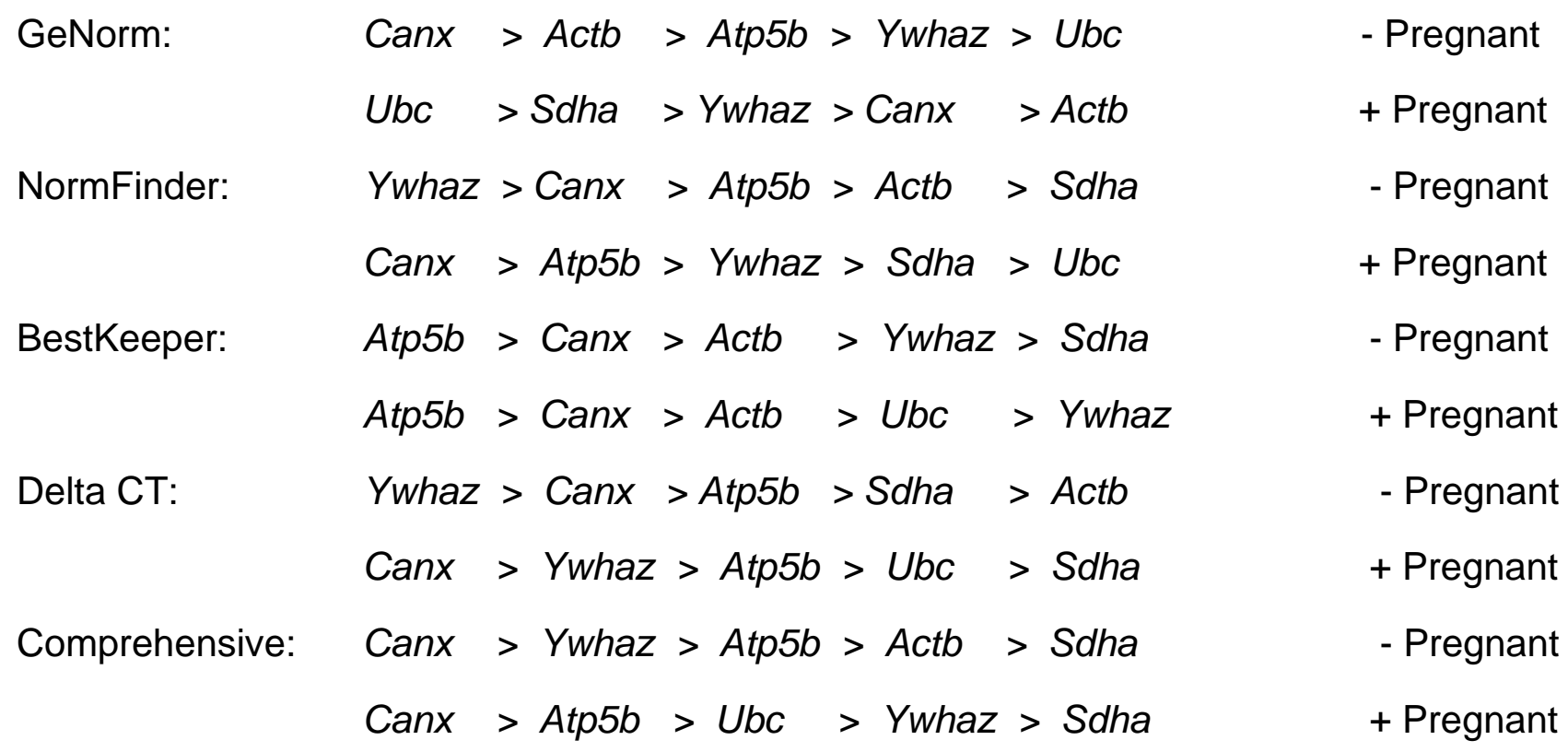

Pituitary:

GeNorm: $\quad$ Sdha $>C y c 1>U b c>A t p 5 b>$ Actb

- Pregnant

Ubc > Sdha $>$ Atp5b $>18 s>$ Actb

+ Pregnant

NormFinder:

Atp5b > Actb $>$ Cyc1 > 18s > Sdha

- Pregnant

221

Atp5b $>$ Actb $>$ Cyc1 $>$ Ubc > Sdha

+ Pregnant

BestKeeper:

Ywhaz $>$ Canx $>$ Actb $>$ Atp5b $>18 s$

- Pregnant

Ywhaz $>$ Canx $>$ Actb $>$ Atp5b $>18 s$

+ Pregnant

Delta CT:

Atp5b > Cyc1 > Sdha > Actb > Ubc

- Pregnant

Atp5b $>$ Cyc1 $>U b c>$ Actb $>$ Sdha

+ Pregnant

Comprehensive: Atp5b $>U b c>A c t b>C y c 1>S d h a$

- Pregnant

Atp5b $>$ Cyc1 $>$ Sdha $>$ Actb $>U b c$

+ Pregnant 
Ovary:

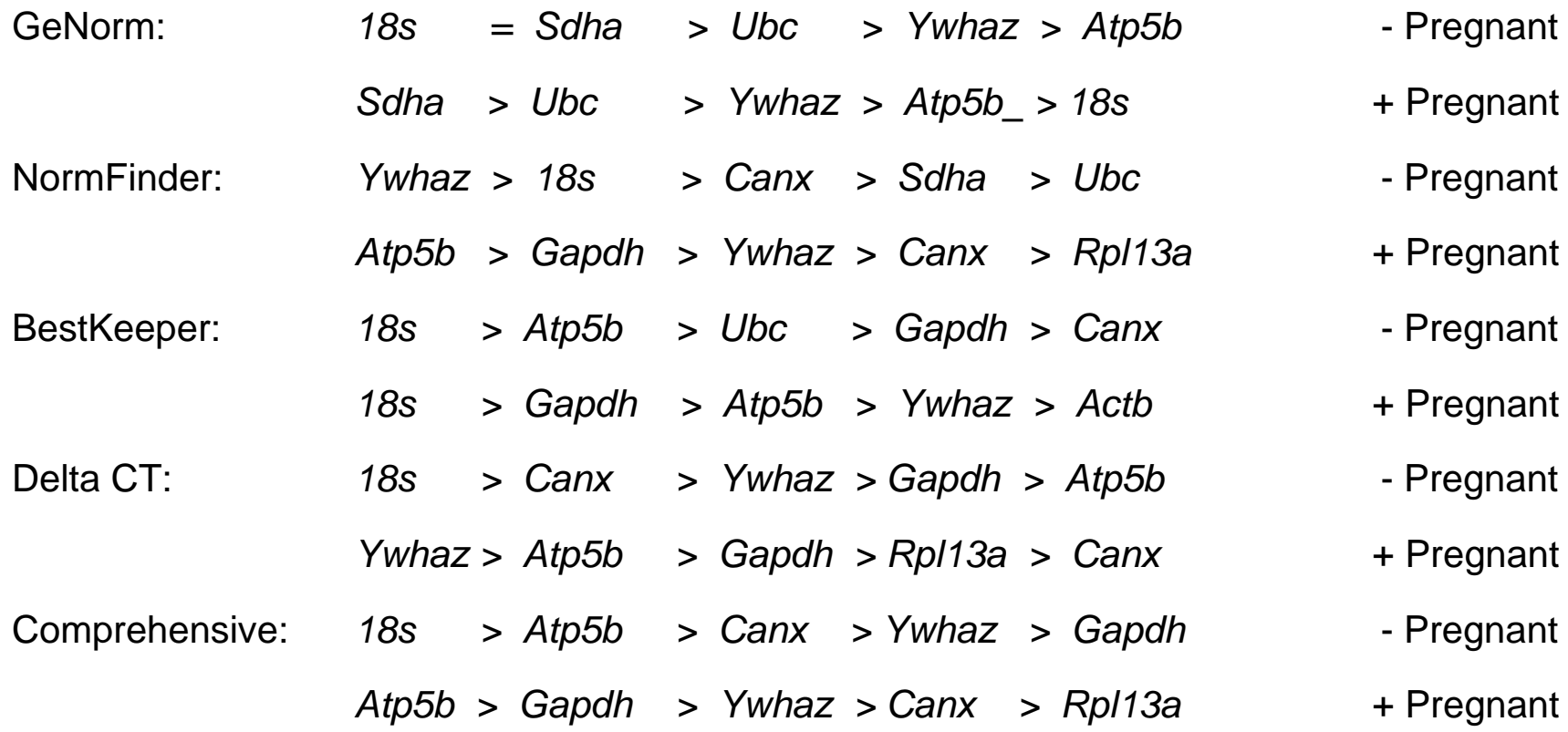

\section{Uterus:}

GeNorm:

Ywhaz > Cyc1 > Atp5b > 18s > Rpl13a

- Pregnant

Ywhaz $>$ Cyc1 $>$ Atp $5 b>18 s>R p / 13 a$

+ Pregnant

NormFinder:

Actb > 18s > Atp5b > Canx > Gapdh

- Pregnant

Actb $>$ Atp5b > 18s > Canx > Gapdh

+ Pregnant

BestKeeper:

Cyc1 > Rpl13a > Atp5b > 18s > Actb

- Pregnant

Ywhaz > Cyc1 > Rpl13a > Atp5b > 18s

+ Pregnant

Delta CT:

Actb > 18s > Atp5b > Canx > Gapdh

- Pregnant

Atp5b > 18s > Actb > Canx > Ywhaz

+ Pregnant

Comprehensive:

Actb $>18 s>A t p 5 b>C y c 1>R p l 13 a$

- Pregnant

Atp5b > Ywhaz $>$ Cyc1 $>18 s>$ Actb

+ Pregnant

In the hypothalamus for the non-pregnant data set, the other tools all identified four of the same genes as the GeNorm tool had as being one of the five most stable genes. Whereas the GeNorm analysis had identified Ubc as also being stable, the other tools all identified Sdha in its place. The rankings did differ between the tools but all identified Canx as one of two most stably expressed 
genes. When the pregnant samples were included the ranking of the five most stable genes changed and Atp5b was replaced by Sdha by the GeNorm tool. The two most stably expressed genes were different to the two most stably expressed genes in the non-pregnant data set using GeNorm. By contrast, both the BestKeeper and Delta CT identified the same pair of genes as being the most stable for both data sets and the other two tools both identified Canx as being one of the two most stable genes in both data sets.

In the pituitary for the non-pregnant data set, both the Delta CT and Comprehensive tools identified the same five most stable genes as the GeNorm tool although the rank order did differ. The GeNorm analysis had identified Sdha and Cyc1 as being the two most stable genes, but only the Delta CT tool also gave Cyc1 in its top two. Three of the tools identified Atp5b as the most stably expressed gene. When the pregnant samples were included the ranking of the five most stable genes changed and Cyc1 was replaced by $18 S$ using GeNorm. The two most stably expressed genes had one in common (Sdha) and Ubc replaced Cyc1 as the two most stably expressed genes. There was variability in the selection of genes and their rank order between the other tools compared to the GeNorm analysis. If only the top two genes are considered all the other tools identified the same genes for both data sets (except the Comprehensive tool which only had one gene in common) unlike the GeNorm analysis but there were differences between the tools as to which two genes were identified.

In the ovary for the non-pregnant data set, the other tools identified three to four of the same genes as the GeNorm tool amongst the five most stable genes. The other tools all identified Canx as one of the top five stably expressed genes but the GeNorm analysis did not. The rankings did differ between the tools but all identified $18 \mathrm{~s}$ as one of two most stably expressed genes. When the pregnant samples were included, the genes identified were the same but the ranking of the five most stable genes changed using GeNorm. The two most stably expressed genes were Sdha and Ubc compared to $18 \mathrm{~s}$ and Sdha as the most stably expressed genes in the non-pregnant data set. Using the other tools with respect to the two most stably expressed genes, the BestKeeper and 
Comprehensive tools both identified the same gene in both data sets (but not the same gene and different from that identified by GeNorm analysis). Both NormFinder and Delta CT had no genes in common between the non-pregnant and with pregnant data sets for the two most stably expressed genes.

In the uterus for the non-pregnant data set, there was variability in the genes identified by each tool. The GeNorm analysis identified Ywhaz as being the most stably expressed but it was not identified as one of the five most stably expressed by any of the other tools. All tools identified Atp5b as the third most stably expressed gene and all included $18 \mathrm{~s}$ in their top five ranking. When the pregnant samples were included the ranking of the five most stable genes was unaltered using GeNorm. The two most stably expressed genes were different to the two most stably expressed genes in the nonpregnant data set. The other tools differed with up to two genes being replaced by others and the rank order changing. The NormFinder, BestKeeper and Delta CT tools all identified one of the two genes most stably expressed as being the same (albeit each a different gene) in both the nonpregnant and with pregnant data sets.

\section{Discussion:}

According to the criteria recommended by the MIQE guidelines, adding more than one reference gene for data normalisation reduces the variability of the RT-qPCR data (Bustin, et al., 2009). The GeNorm analyses for the hypothalamus, pituitary and ovary studied herein confirm that optimally two or more genes should be used instead of a single gene. The $\mathrm{V}$ values for the uterus were above 0.15 hence in this tissue, the use of more than two reference genes would be recommended. The reference gene selection assay included a panel of 12 murine housekeeping genes, however, the amplification efficiencies for $B 2 m$ and Eif4a2 deviated from the accepted range so were not included in these analyses. Ten murine housekeeping genes (18s, Actb, Atp5b, Canx, Cyc1, Gapdh, Rp/13a, Sdha, Ubc and Ywhaz) were therefore investigated for their stability in tissues from the female reproductive axis in pre-weaned, pubertal, adult and pregnant mice. 
The reference genes, 18s, Gapdh and Actb, have been widely used as reference genes for these tissues however in the hypothalamus, 18s and Gapdh were amongst the least stable reference genes. In the pituitary, the $18 \mathrm{~s}$ stability ranking was affected once pregnant samples were included by GeNorm analysis. In the ovary, Actb was the least stable reference gene identified by GeNorm analysis. These findings that $18 \mathrm{~s}$, Gapdh and Actb are potentially pernicious reference genes are consistent with reports in human brain, kidneys and heart as well as rat fetal brain (Vandesompele, et al., 2002; Al-Bader, \& Al-Sarraf, 2005 respectively) . Furthermore, the ranking of expression stability of the reference genes differs in each tissue; for example, tyrosine 3monooxygenase/tryptophan 5-monooxygenase activation protein, zeta polypeptide, Ywhaz, was one of the most stable genes in the hypothalamus, ovary and uterus whilst in the pituitary gland it was the least stable gene. Whilst ranked amongst the 5 most stable genes in the hypothalamus (Sdha was ranked $6^{\text {th }}$ most stable in the non-pregnant data set), pituitary and ovary using the GeNorm tool, both Ubc and Sdha were unstable in the uterus. This highlights the importance of checking the reference gene stability in the context of each experiment as an essential step in quantitative RT-PCR (Bustin, et al., 2009).

All of the reference genes' gene products are known to be involved in essential intracellular functions hence they are expressed in most cells. Their relative expression may be different in some tissues and/or altered by physiological status. Except for the ranking obtained from the BestKeeper tool using the non-pregnant data set, Ywhaz was identified as being one of the most stable genes in the ovaries in both the non-pregnant and with pregnant data sets. Ywhaz encodes for a molecule that forms a hub for several signalling pathways within cells (Sluchanko, 2018). No information on the pattern of Ywhaz expression or its function, and therefore regulation, within the mouse ovary is known. Although Ywhaz (using Gapdh as a reference gene) has been identified as being differentially expressed within the corpus luteum, a transient, hormone-secreting structure of the bovine ovary (Goravanahally, et al., 2009), when tissue was sampled from different areas of the ovary (so with and without tissue of the corpus luteum) and at different times of the oestrous cycle or in pregnancy, the NormFinder and BestKeeper tools but not GeNorm, identified Ywhaz as one of 
the top four most stably expressed genes (Schoen, et al., 2015). In this study we extracted mRNA from entire mouse ovaries taken at different times of the oestrous cycle. The bovine ovary is approximately 500 fold greater in mass than the mouse ovary hence researchers will tend to sample the tissue rather than extracting mRNA from the entire organ. Great care is therefore required when sampling a tissue as heterogeneous as the ovary to ensure it is representative of tissue being investigated. Another example of the differences between tissue and the effects of physiological status effects is Sdha, which produces a subunit of the mitochondrial enzyme, succinate dehydrogenase. Succinate dehydrogenase participates in both the electron transport chain and the citric acid cycle. Although succinate dehydrogenase has essential intracellular functions, its expression will vary since it is well established that the number of mitochondria per cell varies between cell types and that within a cell type can be affected by cell cycle stage and stress (Cole, 2016). Using the GeNorm tool, Sdha was detected as one of the stably expressed genes in the hypothalamus, pituitary gland and the ovary in both the non-pregnant and pregnant data sets. By contrast, it was not regarded as being stably expressed in the uterus in either the non-pregnant or pregnant data sets. The uterus undergoes regular tissue re-modelling in response to hormoneinduced changes over the oestrous cycle in the non-pregnant animal as well as during pregnancy. Others have demonstrated that uterine expression of $18 \mathrm{~s}$, Actb and Gapdh are altered by sex steroids (Durrer, et al., 2005; Craythorn, et al., 2009; Schroder, et al., 2009). Oestrogen receptor 2 (beta), Esr2, has been detected in the mitochondria of the rabbit uterus so it is possible that Sdha uterine expression could be modulated by oestrogen (Monje, \& Boland, 2001).

Other factors that may affect the stability of reference gene expression within a tissue include age and gender. In this study, tissues from pre-weaned (2 week), pubertal (6 week) and adult (10 week and 14 week) animals were included in the GeNorm analyses. Only the BestKeeper tool identified Ywhaz, as one of the top 5 most stable genes in the pituitary. The GeNorm tool identified it as the least stable of the 10 genes in both the non-pregnant and pregnant data sets. This is in stark contrast to a study aimed to identify the most stable genes in both healthy and tumorous pituitaries from humans, mice and dogs (Van Rijn, et al., 2014). Using both the GeNorm and NormFinder tools, 
YWHAZ/Ywhaz was identified as one of the most stable genes in all 3 species and in both healthy and tumorous pituitaries. No information on the gender and age of the subjects for all 3 species, or the breed of the dogs, is provided. These examples all illustrate the care required in providing full descriptions of the samples being compared, even when following the MIQE guidelines, to identify the best experiment-specific reference genes to use.

Although differences have been reported in the mouse brain between day 7 mice and adults (Boda, et al., 2009), we did not observe differences in reference gene stability between pre-weaned and adult mice in either the hypothalamus or pituitary. However, when pregnant adults were also considered, the ranking of gene stability was affected in the hypothalamus, pituitary and ovary with reference genes in the uterus not altered when using the GeNorm analysis. Using the GeNorm tool, adding the pregnant samples to the analysis changed the two most stable genes identified in all the tissues except the uterus. Pregnancy causes substantial gene changes in different systems and axes since the maternal body has to make a myriad of physiological adaptations to maintain the pregnancy. Evidence for these substantial gene changes is supported by RNA-seq and microarray findings: the reference genes overlap many different systemic pathways including inflammatory, metabolic, genetic processing and cellular responses (Mittal, et al., 2015; Knight, et al., 2018). Taken together these findings support the RT-qPCR analyses reported here that pregnancy influences the stability and expression of commonly used reference genes in the hypothalamus, pituitary and ovarian tissue.

There was no apparent effect of pregnancy on the stability of the reference genes in the mouse uterus. Consistent with our findings, reference genes expression analysis of the swine uterus showed similar stability ranking across different reproductive stages except in the later stages of pregnancy (Martínez-Giner, et al., 2013). This study considered mid-pregnancy (day 10), a time when the myometrium of the uterus is quiescent and steroid production by both the ovaries and placentae relative constant. As described above, others have demonstrated that the expression of some commonly used reference genes are altered in the uterus in response to sex steroids, in 
particular oestrogen (Durrer, et al., 2005; Craythorn, et al., 2009; Schroder, et al., 2009). It is anticipated therefore that there may be differences in reference gene expression in early pregnancy, when the endometrium of the uterus undergoes decidualization to provide support to the newly implanted embryos whilst the placentae are establishing, and then again at the end of the pregnancy when the myometrium undergoes many changes to enable it to act as a syncytium during parturition. At both these stages there are significant changes from the normal hormonal milieu.

Another criterion investigated in this study were the different algorithms that investigate reference gene expression stability. There are various applications and software packages that are designed for this purpose and each one of them might produce different patterns of stability depending on the calculation method used (Kozera, \& Rapacz, 2013). In the present study, we have used the GeNorm analysis, which is based on the delta delta CT method, as our reference tool. This analysis has been criticised due to the influence of PCR efficiencies where GeNorm data can be skewed if these efficiencies vary from $100 \%$ (Robledo, et al., 2014). However, GeNorm analysis has been the most commonly adopted tool by researchers as it also enables the determination of the optimum number of reference genes to be selected based on a pairwise variation of $n$ versus $n+1$ reference genes (De Spiegelaere, et al., 2015). The MIQE guideline criteria emphasise the use of more than one reference gene for data normalisation and GeNorm software is the only software that includes this criterion in the reference genes stability analysis. The addition of pregnant samples to the analysis altered the gene pair to be used as references when using the GeNorm analysis for the hypothalamus, pituitary and ovary but the same effect was only detected using the Bestkeeper or Delta CT tools with the ovary. For each of the tissues the least concurrence in the genes found to be the five most stable were those identified by the GeNorm analysis. Other studies have also observed differences in reference gene stability using the BestKeeper analysis (Petriccione, et al., 2015; Garson, et al., 2019) perhaps because the BestKeeper analysis relies on the use of noncorrected raw Cq values, which is a completely different approach to the expression stability analysis 
compared to the other software (De Spiegelaere, et al., 2015). It is therefore unclear which is the ideal tool to use and further research is required.

From this study, we conclude that it is necessary to examine the stability of the reference genes before conducting any gene expression analyses using RT-qPCR. Another essential aspect to consider is the examination of the expression stability of reference genes according to the experimental conditions of any research; if the experimental conditions are to be changed the expression stability needs to be checked again to ensure there are no fluctuations in the expression of the stable genes. Once a gene is found to be stable in a tissue, investigators should be alert to the influences of physiological status on the reference genes; we have found that inclusion of pregnant samples affects the ranking of gene stability in the hypothalamus, pituitary and ovary but not uterus. This is likely due to the significant changes required to enable the maternal physiological adaptations to pregnancy and further investigation is merited to determine whether the stage of pregnancy elicits different changes in reference gene stability.

\section{References}

Al-Bader, M. D. and Al-Sarraf, H. A., (2005). Housekeeping gene expression during fetal brain development in the rat-validation by semi-quantitative RT-PCR. Developmental Brain Research, 156(1), pp.38-45.

Andersen, C.L., Jensen, J.L. and Ørntoft, T.F., (2004). Normalization of real-time quantitative reverse transcription-PCR data: A model-based variance estimation approach to identify genes suited for normalization, applied to bladder and colon cancer data sets. Cancer Research, 64(15), 5245-5250.

Boda, E., Pini, A., Hoxha, E., Parolisi, R. and Tempia, F., (2009). Selection of reference genes for quantitative real-time RT-PCR studies in mouse brain. Journal of Molecular Neuroscience, 37(3), 238-253. 
Bustin, S.A., Benes, V., Garson, J.A., Hellemans, J., Huggett, J., Kubista, M., Mueller, R., Nolan, T., Pfaffl, M.W., Shipley, G.L., Vandesompele, J. and Wittwer, C.T., (2009). The MIQE guidelines: Minimum information for publication of quantitative real-time PCR experiments. Clinical Chemistry, 55(4), 611-622.

Cole, L.W., (2016). The evolution of per-cell organelle number. Frontiers in Cell and Developmental Biology, 4(AUG).

Craythorn, R.G., Girling, J.E., Hedger, M.P., Rogers, P.A.W. and Winnall, W.R., (2009). An RNA spiking method demonstrates that $18 \mathrm{~S}$ rRNA is regulated by progesterone in the mouse uterus. Molecular Human Reproduction, 15(11), 757-761.

Durrer, S., Maerkel, K., Schlumpf, M. and Lichtensteiger, W., (2005). Estrogen target gene regulation and coactivator expression in rat uterus after developmental exposure to the ultraviolet filter 4-methylbenzylidene camphor. Endocrinology, 146(5), 2130-2139.

Garson, J.A., Usher, L., Al-Chalabi, A., Huggett, J., Day, E.F. and McCormick, A.L., (2019). Quantitative analysis of human endogenous retrovirus- $K$ transcripts in postmortem premotor cortex fails to confirm elevated expression of HERV-K RNA in amyotrophic lateral sclerosis. Acta neuropathologica communications, 7(1), 45.

Goravanahally, M.P., Salem, M., Yao, J., Inskeep, E.K. and Flores, J.A., (2009). Differential gene expression in the bovine corpus luteum during transition from early phase to midphase and its potential role in acquisition of luteolytic sensitivity to prostaglandin F2 alpha. Biology of Reproduction, 80(5), 980-988.

Knight, A.K., Dunlop, A.L., Kilaru, V., Cobb, D., Corwin, E.J., Conneely, K.N. and Smith, A.K., (2018). Characterization of gene expression changes over healthy term pregnancies. PLoS ONE, 13(10).

Kozera, B. and Rapacz, M., (2013). Reference genes in real-time PCR. Journal of Applied 
Martínez-Giner, M., Noguera, J.L., Balcells, I., Fernández-Rodríguez, A. and Pena, R.N., (2013). Selection of Internal Control Genes for Real-Time Quantitative PCR in Ovary and Uterus of Sows across Pregnancy. PLOS ONE, 8(6).

Mittal, A., Pachter, L., Nelson, J.L., Kjrgaard, H., Smed, M.K., Gildengorin, V.L., Zoffmann, V., Hetland, M.L., Jewell, N.P., Olsen, J. and Jawaheer, D., (2015). Pregnancy-induced changes in systemic gene expression among healthy women and women with rheumatoid arthritis. PLOS ONE, 10(12).

Monje, P. and Boland, R., (2001). Subcellular distribution of native estrogen receptor $\alpha$ and $\beta$ isoforms in rabbit uterus and ovary. Journal of Cellular Biochemistry, 82(3), 467-479.

Palombella, S., Pirrone, C., Cherubino, M., Valdatta, L., Bernardini, G. and Gornati, R., (2017). Identification of reference genes for GPCR analysis during hASC long culture maintenance. PLOS ONE, 12(2), e0170918.

Petriccione, M., Mastrobuoni, F., Zampella, L. and Scortichini, M., (2015). Reference gene selection for normalization of RT-qPCR gene expression data from Actinidia deliciosa leaves infected with Pseudomonas syringae pv. Actinidiae. Scientific Reports, $\mathbf{5}$.

Pfaffl, M.W., Tichopad, A., Prgomet, C. and Neuvians, T.P., (2004). Determination of stable housekeeping genes, differentially regulated target genes and sample integrity: BestKeeperExcel-based tool using pair-wise correlations. Biotechnology letters, 26(6), 509-15.

Radonić, A., Thulke, S., Mackay, I.M., Landt, O., Siegert, W. and Nitsche, A., (2004). Guideline to reference gene selection for quantitative real-time PCR. Biochemical and Biophysical Research Communications, 313(4), 856-862.

Van Rijn, S.J., Riemers, F.M., Van Den Heuvel, D., Wolfswinkel, J., Hofland, L., Meij, B.P. and Penning, L.C., (2014). Expression stability of reference genes for quantitative RT-PCR of 
healthy and diseased pituitary tissue samples varies between humans, mice, and dogs. Molecular Neurobiology, 49(2), 893-899.

Robledo, D., Hernández-Urcera, J., Cal, R.M., Pardo, B.G., Sánchez, L., Martínez, P. and Viñas, A., (2014). Analysis of qPCR reference gene stability determination methods and a practical approach for efficiency calculation on a turbot (Scophthalmus maximus) gonad dataset. BMC Genomics, 15(1), 1.

Schoen, K., Plendl, J., Gabler, C. and Kaessmeyer, S., (2015). Identification of Stably Expressed Reference Genes for RT-qPCR Data Normalization in Defined Localizations of Cyclic Bovine Ovaries. Journal of Veterinary Medicine Series C: Anatomia Histologia Embryologia, 44(3), 200-211.

Schroder, A.L., Pelch, K.E. and Nagel, S.C., (2009). Estrogen modulates expression of putative housekeeping genes in the mouse uterus. Endocrine, 35(2), 211-219.

Sluchanko, N.N., (2018). Association of Multiple Phosphorylated Proteins with the 14-3-3 Regulatory Hubs: Problems and Perspectives. Journal of Molecular Biology, 430(1), 20-26.

De Spiegelaere, W., Dern-Wieloch, J., Weigel, R., Schumacher, V., Schorle, H., Nettersheim, D., Bergmann, M., Brehm, R., Kliesch, S., Vandekerckhove, L. and Fink, C., (2015). Reference gene validation for RT-qPCR, a note on different available software packages. PLoS ONE, 10(3).

Suzuki, T., Higgins, P.J. and Crawford, D.R., (2000). Control selection for RNA quantitation. BioTechniques, 29(2), 332-337.

Vandesompele, J., De Preter, K., Pattyn, F., Poppe, B., Van Roy, N., De Paepe, A. and Speleman, F., (2002). Accurate normalization of real-time quantitative RT-PCR data by geometric averaging of multiple internal control genes. Genome biology, 3(7), 34-1.

Warrington, J.A., Nair, A., Mahadevappa, M. and Tsyganskaya, M., (2000). Comparison of human 
509 adult and fetal expression and identification of 535 housekeeping/maintenance genes.

$510 \quad$ Physiological Genomics, 2000(2), 143-147.

511 Xie, F., Xiao, P., Chen, D., Xu, L. and Zhang, B., (2012). miRDeepFinder: A miRNA analysis tool 512 for deep sequencing of plant small RNAs. Plant Molecular Biology, 80(1), 75-84. 
515 Table 1: Reference genes with their accession numbers (GeNorm kit, PrimerDesign), reference

516 genes names, function, accession numbers, anchor nucleotide and product length. PCR amplicon

517 sizes were confirmed independently with $2 \%$ agarose gel electrophoresis.

\begin{tabular}{|c|c|c|c|c|c|}
\hline Gene & Full name of the gene name & Function & $\begin{array}{l}\text { Accession } \\
\text { number }\end{array}$ & $\begin{array}{l}\text { Anchor } \\
\text { nucleotide }\end{array}$ & $\begin{array}{l}\text { Amplicon } \\
\text { size (bp) }\end{array}$ \\
\hline $18 \mathrm{~s}$ & $18 \mathrm{~S}$ ribosomal RNA & RNA constituent & NR_003278.3 & 134 & 93 \\
\hline Actb & $\beta$-actin & $\begin{array}{l}\text { Nucleosome binding } \\
\text {-cytoskeleton } \\
\text { component }\end{array}$ & NM_007393.3 & 597 & 84 \\
\hline Atp5b & ATP synthase & ATP biosynthesis & NM_016774.3 & 1115 & 112 \\
\hline$B 2 m$ & $\beta$-2-microglobulin & Glycoprotein binding & NM_009735.3 & 202 & 120 \\
\hline Canx & Calnexin & $\mathrm{Ca}^{+}$binding activity & NM_007597.3 & 2827 & 105 \\
\hline Cyc1 & Cytochrome c isoform 1 & Electron activity & NM_025567.2 & 514 & 141 \\
\hline Eif4a2 & $\begin{array}{l}\text { eukaryotic translation initiation } \\
\text { factor } 4 A 2\end{array}$ & $\begin{array}{l}\text { ATPase and helicase } \\
\text { activity }\end{array}$ & NM_013506.2 & 876 & 152 \\
\hline Gapdh & $\begin{array}{l}\text { glyceraldehyde-3-phosphate } \\
\text { dehydrogenase }\end{array}$ & Metabolism & NM_008084.2 & 793 & 127 \\
\hline Rp/13a & ribosomal protein L13a & RNA constituent & NM_009438.5 & 691 & 130 \\
\hline Sdha & $\begin{array}{l}\text { succinate dehydrogenase } \\
\text { complex flavoprotein subunit A }\end{array}$ & $\begin{array}{l}\text { Mitochondrial } \\
\text { electron transport }\end{array}$ & NM_023281.1 & 2018 & 133 \\
\hline Ubc & ubiquitin $\mathrm{C}$ & Protease binding & NM_019639.4 & 2225 & 129 \\
\hline Ywhaz & $\begin{array}{l}\text { Tyrosine 3- } \\
\text { Monooxygenase/Tryptophan 5- } \\
\text { Monooxygenase Activation } \\
\text { Protein Zeta }\end{array}$ & Cell signalling & NM_011740.3 & 1045 & 141 \\
\hline
\end{tabular}


Table 2: The PCR efficiencies and $R^{2}$ coefficients values for the reference genes in the female (pregnant + age groups) mouse hypothalamus, pituitary gland, ovary and uterus. The PCR efficiency was conducted using standard curves (1:10 dilution covering 5 orders of magnitude) with a starting concentration of the cDNA $(1 \mu \mathrm{g})$. The cDNA was pooled from all age groups and pregnant samples for each tissue separately.

*: genes with poor efficiency that is deviate from the accepted range.

\begin{tabular}{|c|c|c|c|}
\hline \multicolumn{4}{|c|}{ HYPOTHALAMUS } \\
\hline $\begin{array}{c}\text { Reference } \\
\text { gene }\end{array}$ & $\begin{array}{c}\text { PCR } \\
\text { efficiency } \\
(\%)\end{array}$ & $\begin{array}{c}\mathrm{R}^{2} \\
\text { Coefficient }\end{array}$ & M (Slope) \\
\hline 18S & 97 & 0.9876 & -3.39 \\
\hline ACTB & 95 & 0.9906 & -3.45 \\
\hline ATP5B & 99 & 0.9902 & -3.34 \\
\hline B2M* & 73 & 0.8591 & -4.2 \\
\hline CANX & 96.45 & 0.986 & -3.41 \\
\hline CYC1 & 105 & 0.9905 & -3.2 \\
\hline EIF4A2* & 135 & 0.8267 & -2.7 \\
\hline GAPDH & 108.20 & 0.9694 & -3.14 \\
\hline RPL13A & 98 & 0.9911 & -3.37 \\
\hline SDHA & 101 & 0.9911 & -3.28 \\
\hline UBC & 100 & 0.9908 & -3.32 \\
\hline YWHAZ & 98 & 0.9875 & -3.36 \\
\hline
\end{tabular}

\begin{tabular}{|c|c|c|c|}
\hline \multicolumn{4}{|c|}{ PITUITARY } \\
\hline $\begin{array}{c}\text { Reference } \\
\text { gene }\end{array}$ & $\begin{array}{c}\text { PCR } \\
\text { efficiency } \\
(\%)\end{array}$ & $\begin{array}{c}\mathrm{R}^{2} \\
\text { Coefficien } \\
\mathrm{t}\end{array}$ & $\mathrm{M}$ (Slope) \\
\hline 18S & 104 & 0.9943 & -3.22 \\
\hline ACTB & 98 & 0.9765 & -3.371 \\
\hline ATP5B & 102 & 0.9907 & -3.27 \\
\hline B2M $^{*}$ & 83.9 & 0.9409 & -3.78 \\
\hline CANX $^{2}$ & 95 & 0.9902 & -3.44 \\
\hline CYC1 & 98.96 & 0.99 & -3.347 \\
\hline EIF4A2* & 145.8 & 0.7646 & -2.56 \\
\hline GAPDH & 101.8 & 0.9899 & -3.28 \\
\hline RPL13A & 93 & 0.9776 & -3.5 \\
\hline SDHA & 95 & 0.9854 & -3.45 \\
\hline UBC & 97 & 0.9907 & -3.389 \\
\hline YWHAZ & 100 & 0.9913 & -3.319 \\
\hline
\end{tabular}

\begin{tabular}{|c|c|c|c|}
\hline \multicolumn{4}{|c|}{ OVARY } \\
\hline $\begin{array}{c}\text { Reference } \\
\text { gene }\end{array}$ & $\begin{array}{c}\text { PCR } \\
\text { efficiency } \\
(\%)\end{array}$ & $\begin{array}{c}\mathrm{R}^{2} \\
\text { Coefficient }\end{array}$ & $\mathrm{M}$ (Slope) \\
\hline 18S & 99 & 0.9894 & -3.342 \\
\hline ACTB & 90 & 0.99 & -3.578 \\
\hline ATP5B & 100 & 0.9906 & -3.298 \\
\hline B2M* & 86.64 & 0.9691 & -3.69 \\
\hline CANX & 100 & 0.99 & -3.323 \\
\hline CYC1 & 93 & 0.9743 & -3.51 \\
\hline EIF4A2* & 121.8 & 0.943 & -2.891 \\
\hline GAPDH & 98.82 & 0.9922 & -3.352 \\
\hline RPL13A & 96 & 0.9961 & -3.42 \\
\hline SDHA & 100.97 & 0.9878 & -3.299 \\
\hline UBC & 100 & 0.99 & -3.317 \\
\hline YWHAZ & 100 & 0.9759 & -3.32 \\
\hline
\end{tabular}

\begin{tabular}{|c|c|c|c|}
\hline \multicolumn{4}{|c|}{ UTERUS } \\
\hline $\begin{array}{c}\text { Reference } \\
\text { gene }\end{array}$ & $\begin{array}{c}\text { PCR } \\
\text { efficiency } \\
(\%)\end{array}$ & $\begin{array}{c}\mathrm{R}^{2} \\
\text { Coefficien } \\
\mathrm{t}\end{array}$ & M (Slope) \\
\hline 18S & 100 & 0.9934 & -3.316 \\
\hline ACTB & 98.39 & 0.9917 & -3.361 \\
\hline ATP5B & 95 & 0.9794 & -3.45 \\
\hline B2M $^{*}$ & 78.34 & 0.8795 & -3.98 \\
\hline CANX & 99.66 & 0.9834 & -3.33 \\
\hline CYC1 & 100 & 0.9956 & -3.322 \\
\hline EIF4A2* & 137.65 & 0.9306 & -2.66 \\
\hline GAPDH & 97 & 0.9929 & -3.389 \\
\hline RPL13A & 100 & 0.986 & -3.318 \\
\hline SDHA & 93 & 0.9991 & -3.53 \\
\hline UBC & 101.78 & 0.9762 & -3.28 \\
\hline YWHAZ & 100 & 0.9947 & -3.324 \\
\hline
\end{tabular}


Figure 1: Box and whiskers plot showing the mean CT distribution of reference genes in the female mouse hypothalamus, pituitary gland, ovary and uterus with tissues from ages 2, 6, 9, 10 and 14 weeks where $n=3$. The mean CT is represented by $(+)$ within the box for each reference gene, the line in the box represents the median value and the whiskers at each end of the box represent the minimum and maximum values.

Hypothalamus
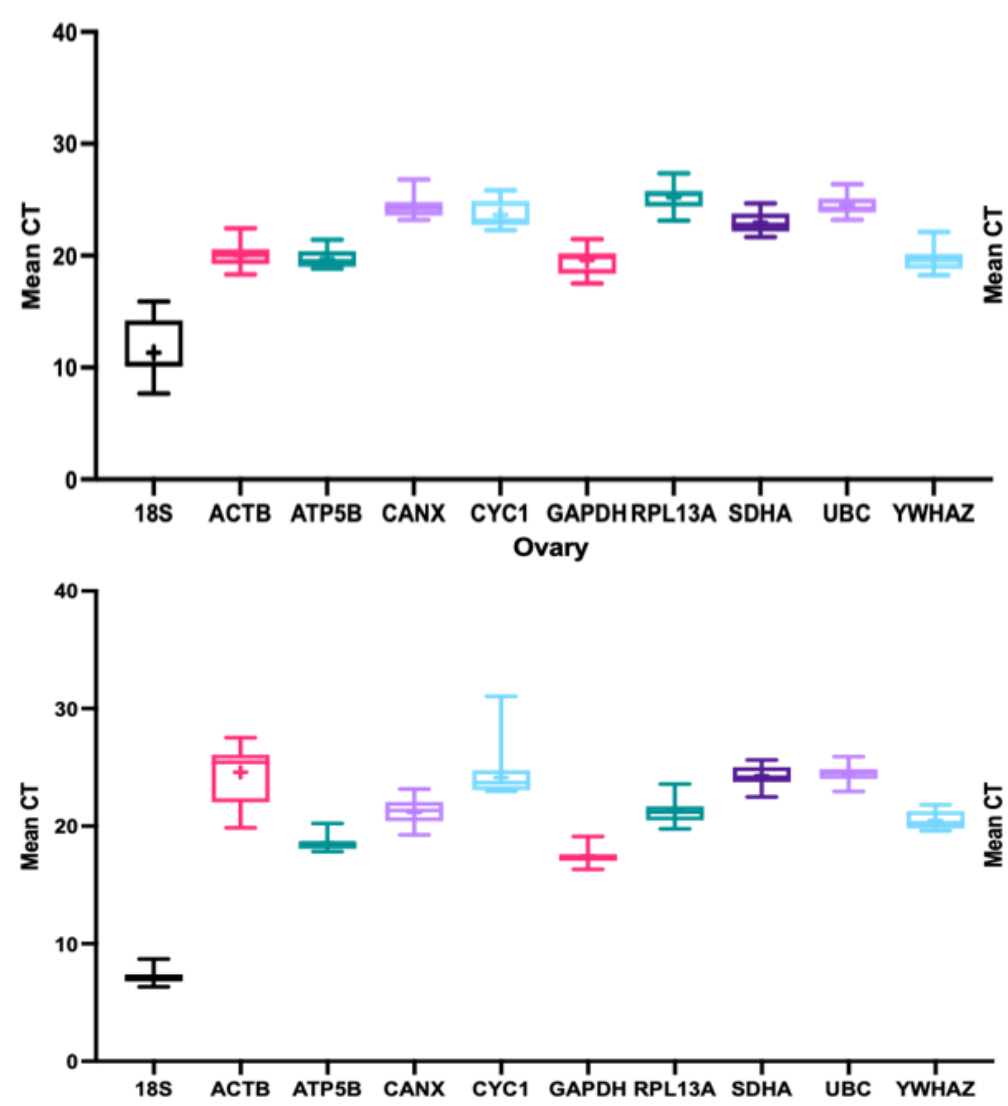

Pituitary gland
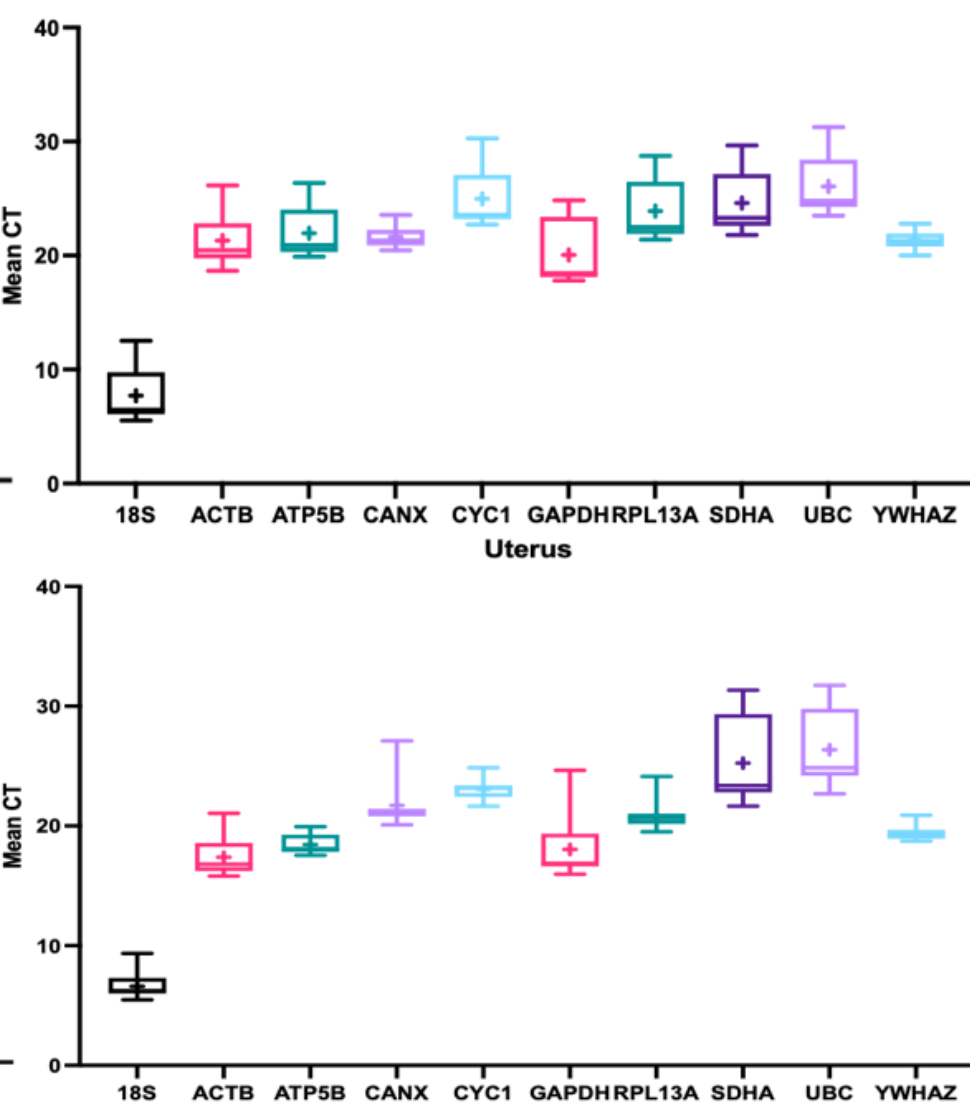
Figure 2: Determination of the optimal number of stable reference genes to be used in normalisation using a variation score (V-score) by GeNorm. V-score below 0.15 indicates insignificance of adding more reference genes for normalisation. The optimal number of reference genes with the age group only and the ages plus the pregnant samples did not change; data below is shown for the ages only. A comparison between two consecutive candidate reference genes (n vs. $n+1$ ) for the non-pregnant: hypothalamus, pituitary, ovary and uterus. This is plotted as the variation score or the $\mathrm{V}$ value, which was obtained automatically by the GeNorm, qBase ${ }^{+}$ software.

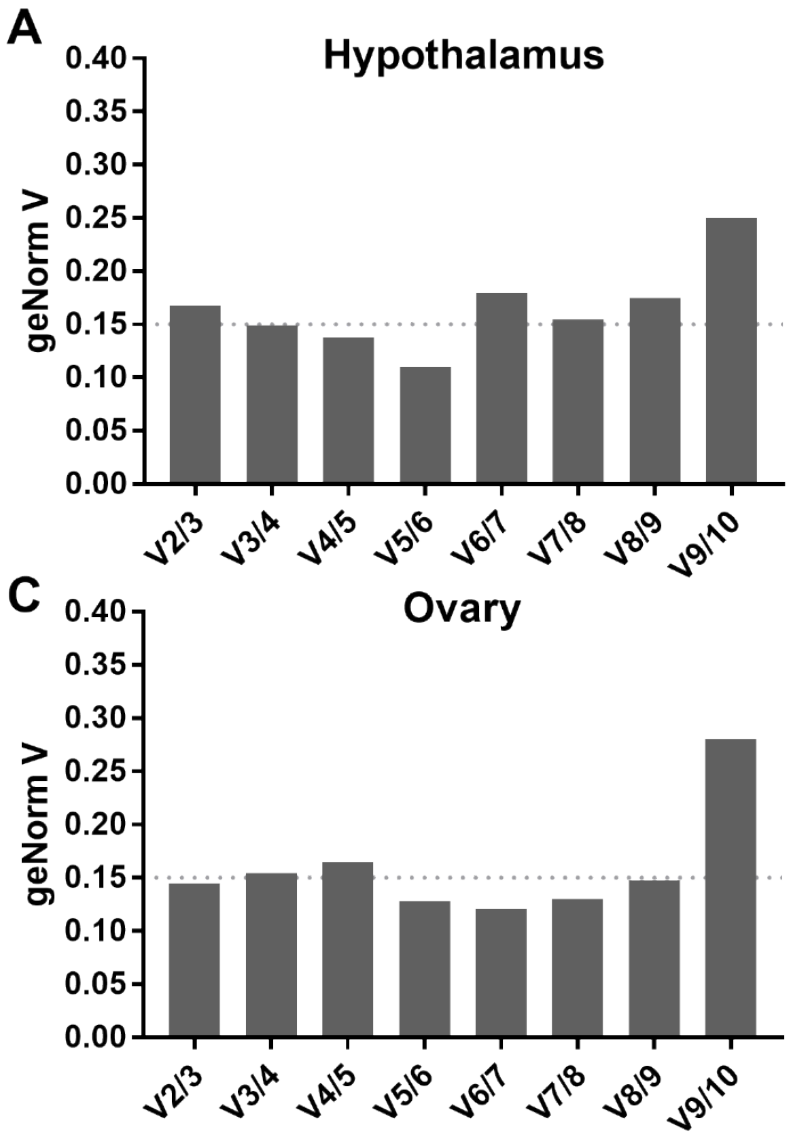

Pairwise variation $(\mathrm{Vn} / \mathrm{Vn}+1)$

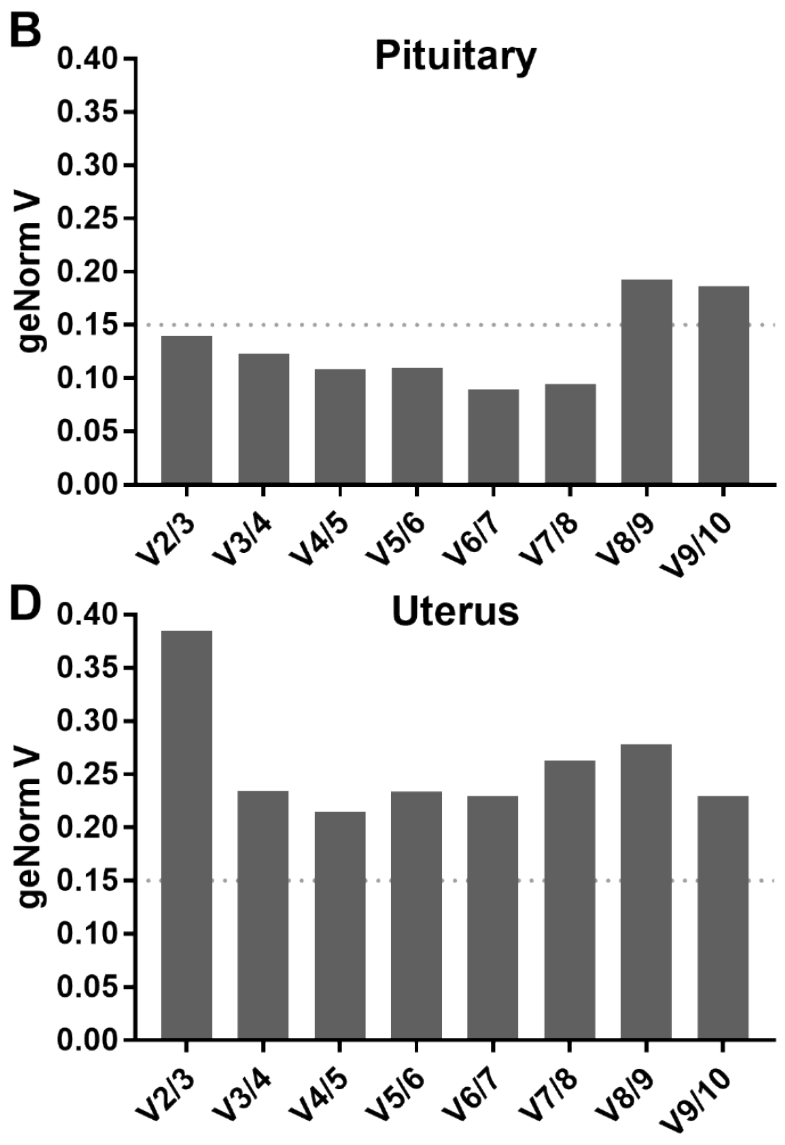

Pairwise variation $(\mathrm{Vn} / \mathrm{Vn}+1)$ 
Figure 3: GeNorm analysis. 18s, Actb, Atp5b, Canx, Cyc1, Gapdh, Rpl13a, Sdha, Ubc and Ywhaz expression stabilities were investigated in the female mouse hypothalamus (A1, B1), pituitary (A2, B2), ovary (A3, B3) and uterus (A4, B4). The samples were divided in to two groups: the age group which included samples from mice aged 2, 6, 9, 10 and 14 weeks (A14) and a second group (+ pregnant) which included these ages plus $13 \mathrm{dpc}$ pregnant mice (B1-4). The data were analysed using GeNorm in qBase ${ }^{+}$(Biogazelle, Belgium). The most stably expressed genes are displayed on the left hand side of each figure (A1-B4) with the least stably expressed genes on the right hand side. 
Hypothalamus (- pregnant)

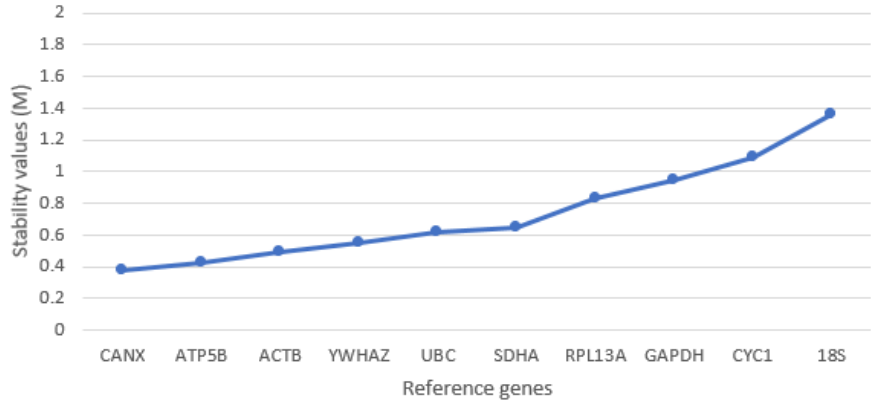

A1

Pituitary gland (- pregnant)

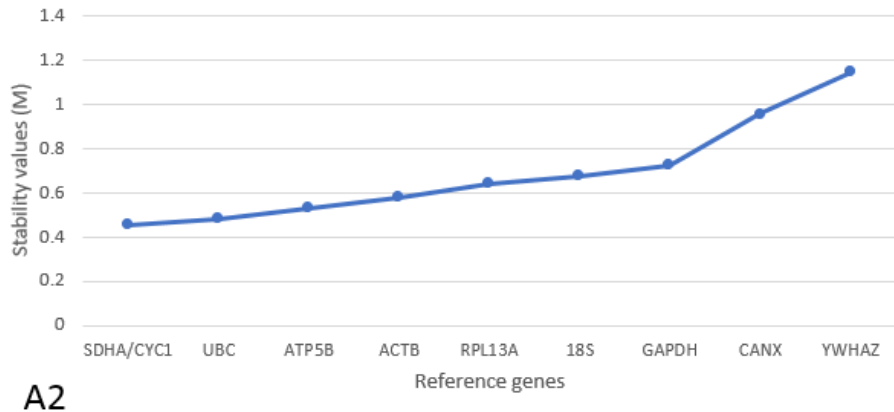

Ovary (- pregnant)

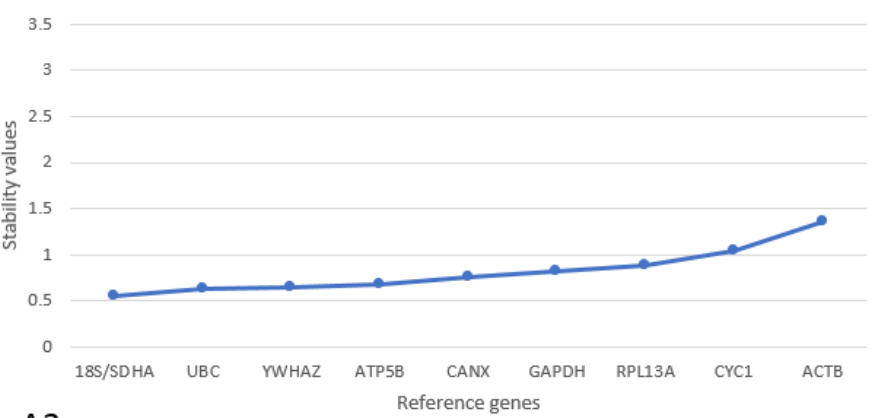

A3

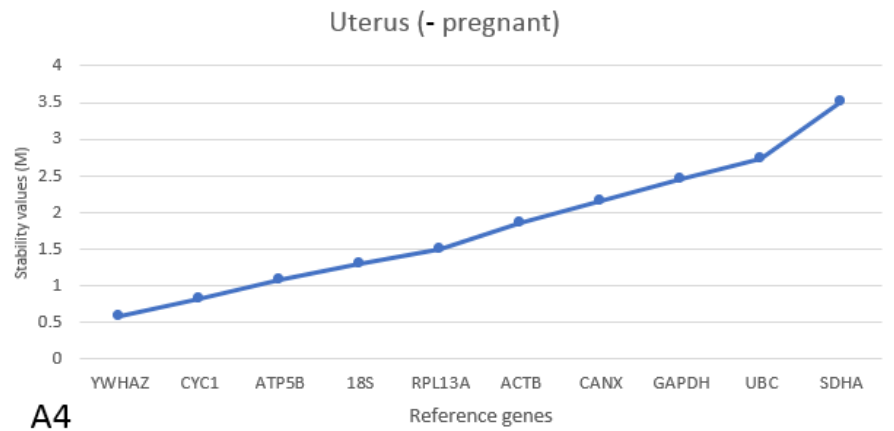

Hypothalamus (+ pregnant)

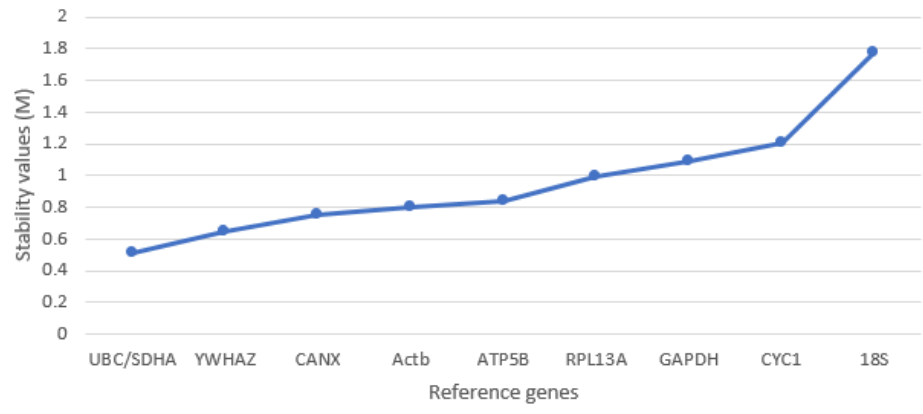

B1

Pituitary gland (+ pregnant)

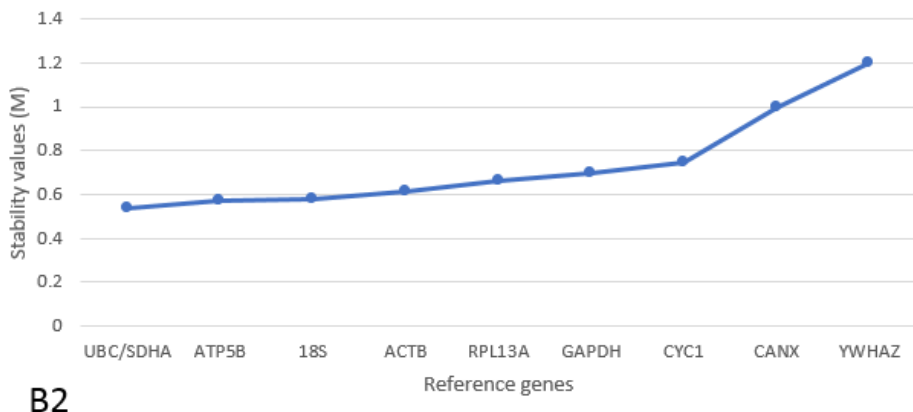

Ovary (+ pregnant)

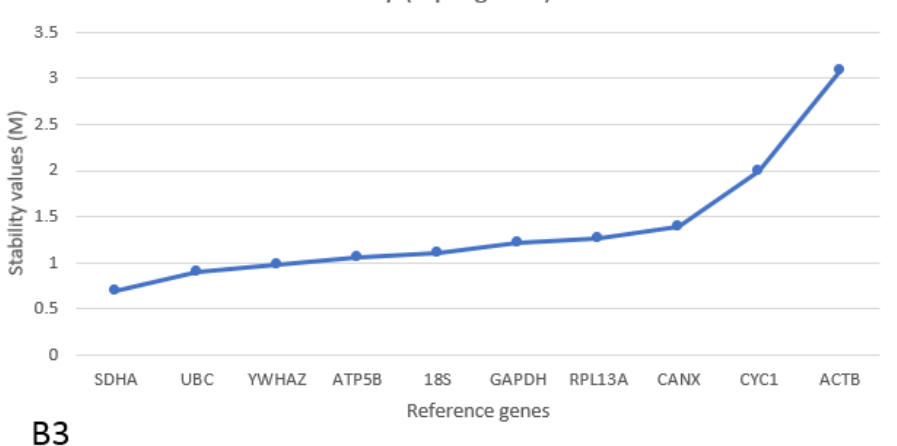

Uterus (+ pregnant)

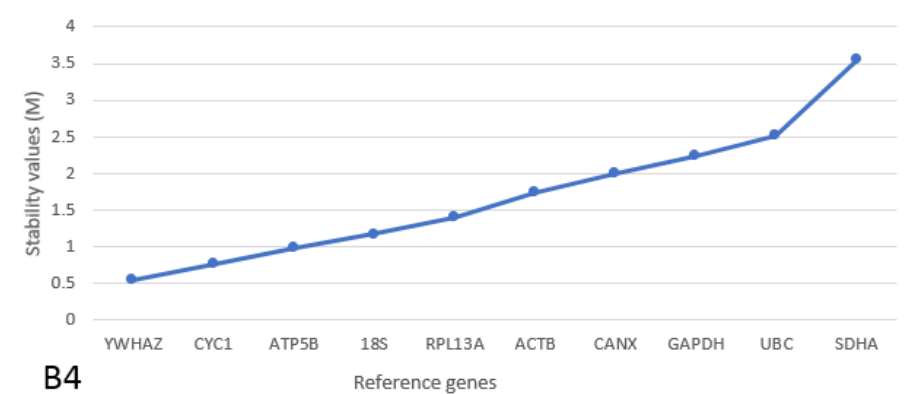

MOST STABLE 